\title{
Two New ent-Kaurane Diterpenoids from Albizia mollis (Wall.) Boiv.
}

\author{
Zhong-Quan Cheng, ${ }^{a, b}$ Dan Yang, ${ }^{a}$ Yu-Qing Liu, ${ }^{a}$ Jiang-Miao Hu, ${ }^{a}$ He-Zhong Jiang, ${ }^{a}$ \\ Peng-Cheng Wang, ${ }^{a}$ Ning Li, ${ }^{c}$ Jun Zhou ${ }^{a}$ and You-Xing Zhao ${ }^{*, a}$
}

${ }^{a}$ State Key Laboratory of Phytochemistry and Plant Resources in West China, Kunming Institute of Botany, the Chinese Academy of Sciences, Kunming 650204, P. R. China

${ }^{b}$ Graduate School of the Chinese Academy of Sciences, Beijing 100049, P. R. China

'School of Life Sciences, Anhui University, Hefei 230039, P. R. China

\begin{abstract}
Dois novos diterpenos com esqueleto caurano, $3 \alpha, 16 \beta$-17-tri-hidróxi-ent-caurano 3-O- $\beta$-Dglucopiranosídeo e ácido $2 \beta, 3 \alpha$-di-hidróxi-ent-caur-15-eno-17-óico 3-O- $\beta$-D-glucopiranosídeo, foram isolados das cascas de Albizia mollis (Wall.) Boiv. As estruturas destes dois cauranos foram elucidadas por métodos espectroscópicos uni e bidimensionais e por espectrometria de massas.
\end{abstract}

Two new kaurane diterpenoids, $3 \alpha, 16 \beta, 17$-trihydroxy-ent-kaurane 3-O- $\beta$-D-glucopyranoside and $2 \beta, 3 \alpha$-dihydroxy-ent-kaur-15-en-17-oic acid 3-O- $\beta$-D-glucopyranoside, were isolated from the bark of Albizia mollis (Wall.) Boiv. The structures of two new compounds were elucidated by extensive 1D- and 2D-NMR spectroscopic methods in combination with MS experiments.

Keywords: Albizia mollis, kaurane diterpenoids, mollisside A, mollisside B

\section{Indroduction}

Plant species of Albizia are known for their traditional medicinal uses as medicaments of mind unrest, insomnia, physique damage, carbuncle gall in many parts of tropic zone. In China, Albizia mollis, popularly named "maoyehehuan" is one of representative plant species of this family. This plant is well known for its sedative and sleeping pill properties. ${ }^{1}$ The previous chemical investigations on Albizia species have led to the isolation of lignans, ${ }^{2-5}$ flavonoids, ${ }^{6-9}$ saponins, ${ }^{10}$ alkaloids, ${ }^{11}$ together with other secondary metabolites. ${ }^{12}$ In search for new and bioactive compounds from $A$. mollis, the chemical investigation of this plant, collected from Kunming Botanical Garden, Yunnan Province, People's Republic of China, led to the isolation of two new compounds. This report describes the isolation and structural elucidation of two new ent-kaurane diterpenoids named mollissides A (1) and B (2).

\section{Results and Discussion}

Mollisside A (1) was isolated as white powder. Its molecular formula was determined to be $\mathrm{C}_{26} \mathrm{H}_{44} \mathrm{O}_{8}$ with five

*e-mail: yxzhao@mail.kib.ac.cn unsaturation degrees by HRFABMS $\left(\mathrm{m} / 2483.2959[\mathrm{M}-1]^{-}\right)$ and ${ }^{13} \mathrm{C}$ NMR spectra. The ${ }^{1} \mathrm{H}$ NMR spectrum of compound 1 clearly showed signals to three methyls at $\delta 0.83(3 \mathrm{H}, \mathrm{s}), 1.03$ $(3 \mathrm{H}, \mathrm{s}), 1.07(3 \mathrm{H}, \mathrm{s})$, and one anomeric hydrogen of $\beta$-type sugar at $\delta 4.30(1 \mathrm{H}, \mathrm{d}, J 7.8 \mathrm{~Hz})$. The ${ }^{13} \mathrm{C}$ NMR $\left(\left\{{ }^{1} \mathrm{H}\right\}\right.$ and DEPT) spectroscopic data (Table 1) revealed the presence of 3 methyls, 10 methylenes, 9 methines and 4 quaternary carbons. Carbon signals at $\delta 106.8$ (d), 75.6 (d), 77.7 (d), 71.6 (d), $78.2(\mathrm{~d}), 62.8(\mathrm{t})$ suggested the presence of one glucose, which were further confirmed by its MS fragmentation peaks at $m / z, 323$ [M-1-160 $=\mathrm{C}_{6} \mathrm{H}_{8} \mathrm{O}_{5}$ formed by fragmentation involving glc moiety $\left.\mathrm{C}_{6} \mathrm{H}_{10} \mathrm{O}_{5}\right]^{-}$and the acid hydrolysis of 1. Comparison of these NMR data with those similar data reported in the literature ${ }^{13}$ showed that compound $\mathbf{1}$ had the same ent-kaurane skeleton. The linkage of glucose moiety to C-3 was determined by the HMBC correlations from $\mathrm{H}-1^{\prime}(\delta 4.30), \mathrm{H}-18(\delta 1.03)$ and $\mathrm{H}-19(\delta 0.83)$ to $\mathrm{C}-3(\delta 90.9)$ (Figure 2$)$. The attachment of one hydroxyl at $\mathrm{C}-17$ in 1 was established by HMQC and HMBC spectra revealing correlations of $\mathrm{H}-17(\delta 3.27)$ with $\mathrm{C}-16(\delta 80.7)$, $\mathrm{C}-13(\delta 42.3)$ and $\mathrm{C}-15(\delta$ 53.1). Besides, the relative configuration of $\mathbf{1}$ was elucidated by a ROESY experiment and by comparison of the NMR data with those reported in the literature. ${ }^{14}$ The key ROESY correlations of $\mathrm{H}-3 / \mathrm{H}-18$, $\mathrm{H}-3 / \mathrm{H}-5$ and $\mathrm{H}-9 / \mathrm{H}-5$ (Figure 3), indicated $\alpha$-orientation 


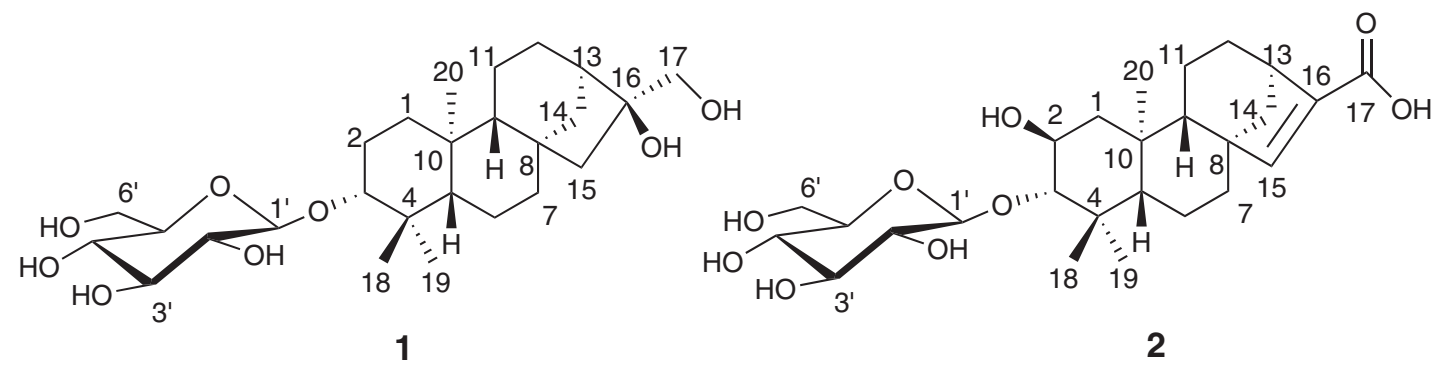

Figure 1. Structures of compounds $\mathbf{1}$ and $\mathbf{2}$.

Table 1. ${ }^{1} \mathrm{H}$ and ${ }^{13} \mathrm{C}$ NMR spectroscopic data for mollisside A (1) and mollisside B (2)

\begin{tabular}{|c|c|c|c|c|}
\hline & \multicolumn{2}{|r|}{1} & \multicolumn{2}{|r|}{2} \\
\hline & $\delta_{c}$ & $\delta_{H}$ & $\delta_{C}$ & $\delta_{H}$ \\
\hline 1 & 43.1 & $1.40(\mathrm{~m}), 1.43(\mathrm{~d}, 2.4)$ & 47.5 & $0.83(\mathrm{~d}, 12.0), 2.22(\mathrm{dd}, 5.0,13.0)$ \\
\hline 2 & 27.2 & $1.72(\mathrm{~m}), 1.95(\mathrm{~m})$ & 68.1 & 3.00 (overlapped), 3.75 (ddd, 5.0, 9.3, 12.0) \\
\hline 3 & 90.9 & $3.15(\mathrm{dd}, 1.2,4.4)$ & 96.1 & $3.00(\mathrm{~d}, 9.3)$ \\
\hline 4 & 40.2 & - & 41.6 & - \\
\hline 5 & 56.9 & $0.80(\mathrm{~d}, 11.6)$ & 56.1 & $0.93(d, 10.7)$ \\
\hline 6 & 20.7 & $1.35(\mathrm{~m}), 1.45(\mathrm{~m})$ & 19.6 & $1.39(\mathrm{~m})$ \\
\hline 7 & 40.0 & $0.90(\mathrm{~m}), 1.85(\mathrm{~m})$ & 39.3 & $1.66(\mathrm{~m})$ \\
\hline 8 & 48.3 & - & 51.4 & - \\
\hline 9 & 58.6 & 1.05 (overlapped) & 48.0 & 1.10 (overlapped) \\
\hline 10 & 44.6 & - & 41.2 & - \\
\hline 11 & 19.8 & $1.95(\mathrm{~m}), 1.60(\mathrm{~d}, 6.4)$ & 19.7 & $1.66(\mathrm{~m})$ \\
\hline 12 & 27.9 & $1.45(\mathrm{~m}), 1.85(\mathrm{~m})$ & 26.5 & $1.63(\mathrm{~m})$ \\
\hline 13 & 42.3 & $2.03(\mathrm{~d}, 3.6)$ & 41.9 & $2.87(\mathrm{~s})$ \\
\hline 14 & 39.2 & $1.03(\mathrm{~m}), 1.98(\mathrm{~d}, 11.6)$ & 44.3 & $1.39(\mathrm{~m}), 2.17(\mathrm{~d}, 9.6)$ \\
\hline 15 & 53.1 & $1.38(\mathrm{~m})$ & 154.7 & $6.48(\mathrm{~s})$ \\
\hline 16 & 80.7 & - & 139.9 & - \\
\hline 17 & 70.6 & $3.27(\mathrm{~m}), 3.38(\mathrm{~d}, 11.2)$ & 164.1 & - \\
\hline 18 & 28.7 & $1.03(\mathrm{~s})$ & 28.9 & $1.12(\mathrm{~s})$ \\
\hline 19 & 16.9 & $0.83(\mathrm{~s})$ & 17.9 & $0.88(\mathrm{~s})$ \\
\hline 20 & 18.2 & $1.07(\mathrm{~s})$ & 19.4 & $1.16(\mathrm{~s})$ \\
\hline $1^{\prime}$ & 106.8 & $4.30(\mathrm{~d}, 7.8)$ & 106.4 & $4.32(\mathrm{~d}, 7.8)$ \\
\hline $2^{\prime}$ & 75.6 & $3.20(\mathrm{~m})$ & 75.5 & $3.35(\mathrm{~m})$ \\
\hline $3^{\prime}$ & 77.7 & $3.26(\mathrm{~m})$ & 78.1 & $3.31(\mathrm{~m})$ \\
\hline $4^{\prime}$ & 71.6 & $3.24(\mathrm{~m})$ & 71.4 & $3.33(\mathrm{~m})$ \\
\hline $5^{\prime}$ & 78.2 & $3.34(\mathrm{~d}, 12.0)$ & 78.2 & $3.30(\mathrm{~m})$ \\
\hline $6^{\prime}$ & 62.8 & $\begin{array}{l}3.67(\mathrm{dd}, 2.0,12.0), \\
3.84(\mathrm{dd}, 5.2,12.0)\end{array}$ & 62.4 & $\begin{array}{c}3.67(\mathrm{dd}, 3.5,11.5) \\
3.85(\mathrm{~d}, 11.5)\end{array}$ \\
\hline
\end{tabular}

of C-3 glycoside and $\beta$-orientations of $\mathrm{H}-5$ and $\mathrm{H}-9$. The $\alpha$-orientation of $\mathrm{CH}_{2} \mathrm{OH}-17(\delta c 70.6)$ in 1 was elucidated by comparison of the ${ }^{13} \mathrm{C}$ NMR data with those reported $\delta c 69.8$ for $\alpha$-orientation and $\delta c 66.2$ for $\beta$-orientation at $\mathrm{C}-17 .{ }^{14}$ Based on the above evidences, compound $\mathbf{1}$ was identified as $3 \alpha, 16 \beta, 17$-trihydroxy-ent-kaurane 3-O- $\beta$-Dglucopyranoside, named Mollisside A.

Mollisside B (2) was determined to have a molecular formula $\mathrm{C}_{26} \mathrm{H}_{40} \mathrm{O}_{9}$ on the basis of the positive HRFABMS $\left(\mathrm{m} / \mathrm{z}\right.$ 519.2565 $\left.[\mathrm{M}+\mathrm{Na}]^{+}\right)$and ${ }^{13} \mathrm{C}$ NMR (DEPT) spectra, which possessed seven unsaturation degrees. Its IR spectrum showed a broad band (3518-2930 $\left.\mathrm{cm}^{-1}\right)$ and absorption $1691 \mathrm{~cm}^{-1}$ for a carboxyl and $1607 \mathrm{~cm}^{-1}$ for a double bond. The ${ }^{1} \mathrm{H}$ NMR spectrum of compound 2 exhibited three methyls at $\delta 0.88(3 \mathrm{H}, \mathrm{s}), 1.12(3 \mathrm{H}, \mathrm{s})$, $1.16(3 \mathrm{H}, \mathrm{s})$, one anomeric proton of $\beta$-type sugar at $\delta 4.32$ $(1 \mathrm{H}, \mathrm{d}, J 7.8 \mathrm{~Hz})$ and one olefinic proton at $\delta 6.48(1 \mathrm{H}$, $\mathrm{s})$. The ${ }^{13} \mathrm{C}$ NMR spectroscopic data (Table 1 ) revealed 26 carbon atoms, including one carboxyl (C-17 at $\delta 164.1)$ and two olefinic carbons (C-16 at $\delta 139.9, \mathrm{C}-15$ at $\delta 154.7)$. Comparison of these NMR data with mollisside A showed that compound $\mathbf{2}$ had the similar skeleton of compound 


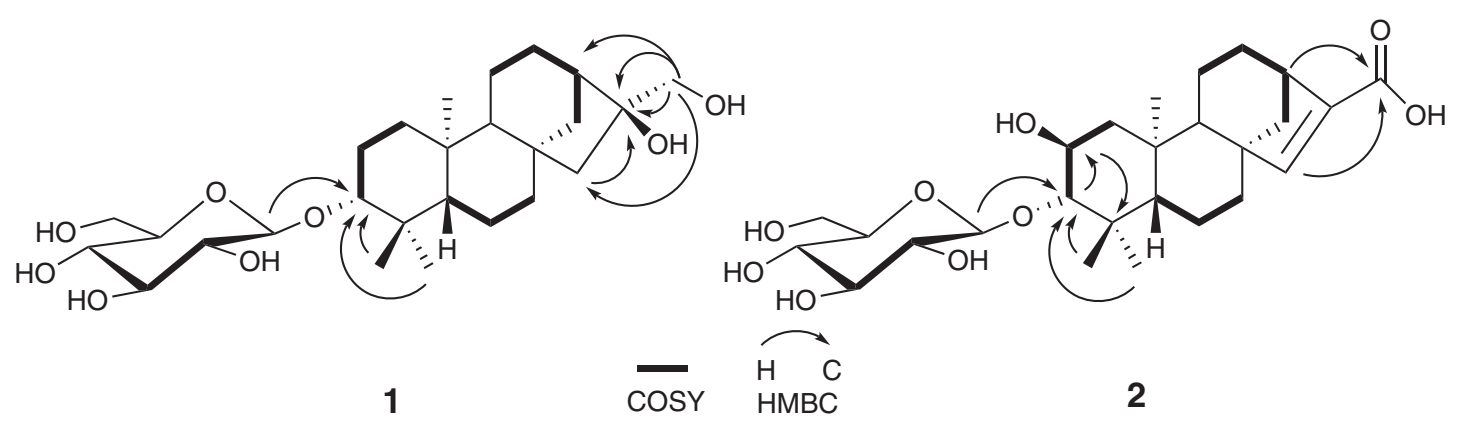

Figure 2. Key COSY and selected HMBC correlations of compounds $\mathbf{1}$ and $\mathbf{2}$.
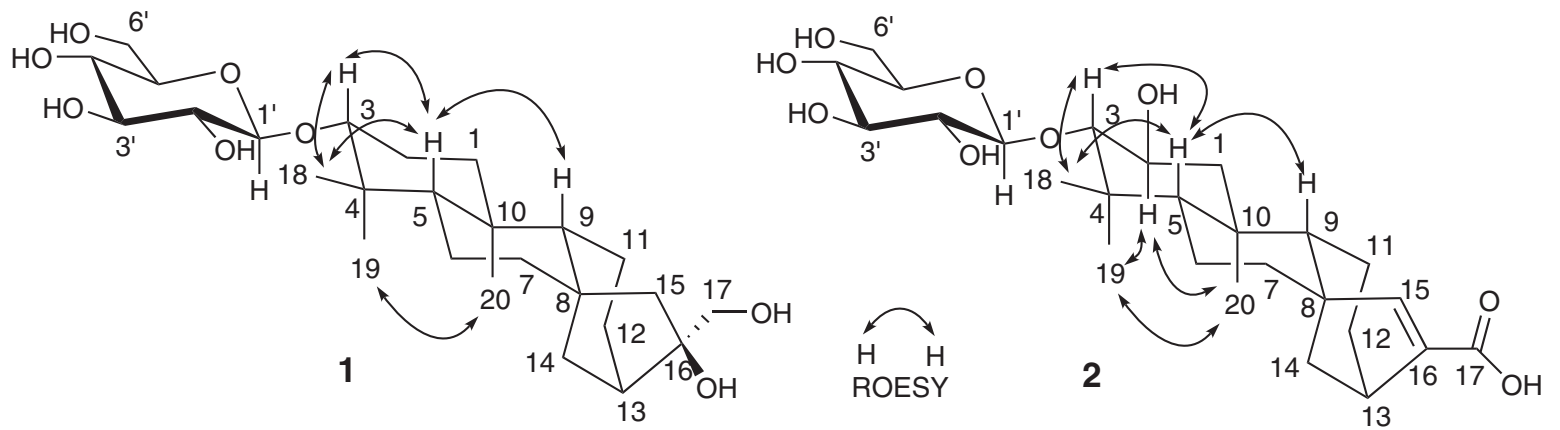

Figure 3. Key ROESY correlations of compounds $\mathbf{1}$ and $\mathbf{2}$.

1 except for the distinct differences of chemical shift of C-2 ( $\delta$ 68.1) adjacent one oxygenated group and C-17, $\mathrm{C}-15$ and $\mathrm{C}-16$ conforming the $\alpha, \beta$-unsaturation ketone system. The linkage of the glucose moietiy to C-3 ( $\delta 96.1)$ was determined by the HMBC correlations from $\mathrm{H}-1^{\prime}$ $(\delta 4.32), \mathrm{H}-18(\delta 1.12)$ and $\mathrm{H}-19(\delta 0.88)$ to C-3 (Figure 2$)$. Besides, the relative configuration of $\mathbf{2}$ was elucidated by a ROESY experiment and by comparison of the NMR data with $\mathbf{1}$. The $\alpha$-orientation of $\mathrm{H}-2$ was established by key ROESY correlations of $\mathrm{H}-2 / \mathrm{H}-1 \alpha, \mathrm{H}-2 / \mathrm{H}-19$ and $\mathrm{H}-2 / \mathrm{H}-20$ (Figure 3) and the coupling constant $J 9.3 \mathrm{~Hz}$ observed in the signal corresponding to $\mathrm{H}-3$ (interaction axial- axial with $\mathrm{H}-2$ ). Moreover, the $\beta$-orientations of $\mathrm{H}-3$, $\mathrm{H}-5$ and $\mathrm{H}-9$ were confirmed by ROESY between $\mathrm{H}-3 / \mathrm{H}-5$, $\mathrm{H}-3 / \mathrm{H}-18$ and $\mathrm{H}-5 / \mathrm{H}-9$. Based on the above evidences, the structure of $\mathbf{2}$ was elucidated as $2 \beta, 3 \alpha$-dihydroxy-entkaur-15-en-17-oic acid 3-O- $\beta$-D-glucopyranoside, named Mollisside B.

\section{Experimental}

\section{General experimental procedures}

Melting points were measured on a XRC-1 micromelting point apparatus and were uncorrected. MS spectra were obtained on a VG Auto Spec-3000 mass spectrometer. 1D and 2D NMR spectra were recorded on Bruker AM-400 MHz and DRX-500 MHz spectrometers, with chemical shifts $(\delta)$ in ppm relative to TMS as internal standard and coupling constants in hertz (Hz). IR spectra were measured with a Bio-Rad FTS-135 spectrometer with $\mathrm{KBr}$ pellets. UV spectra were measured on a Hitachi UV-3210 spectrophotometer. Silica gel (200-300 mesh) for column chromatography was product of the Qingdao Marine Chemical Ltd., Qingdao, P. R. China. Sephadex LH-20 for chromatography was purchased from Amersham Biosciences. Reversed-phase chromatography was with RP-18 (LiChroprep, 40-63 $\mu \mathrm{m}$, Merck, Darmstadt, Germany).

\section{Plant material}

The bark of A. mollis was collected in Kunming Botanical Garden, Yunnan Province, People's Republic of China, in September 2007, and authenticated by Professor Xun Gong. A voucher specimen (ZM080920) has been deposited in the Herbarium of Kunming Institute of Botany, Chinese Academy of Sciences.

\section{Extraction and isolation}

The air-dried and powdered bark of A. mollis $(18.0 \mathrm{~kg})$ was extracted three times each with $20 \mathrm{~L}$ of $95 \% \mathrm{EtOH}$ under reflux for $3 \mathrm{~h}$. The extract was evaporated and the residue $\left(1050 \mathrm{~g}\right.$ ) was resuspended in $15 \mathrm{~L}$ of $\mathrm{H}_{2} \mathrm{O}$ and partitioned successively with EtOAc $(3 \times 5 \mathrm{~L})$ and $\mathrm{n}-\mathrm{BuOH}$ 
$(3 \times 5 \mathrm{~L})$ to yield EtOAc extract $(300 \mathrm{~g}), \mathrm{n}-\mathrm{BuOH}$ extract $(640 \mathrm{~g})$, respectively. Part of $\mathrm{n}-\mathrm{BuOH}$ extract $(500 \mathrm{~g})$ was applied to a silica gel column chromatography (200-300 mesh) eluted with $\mathrm{CHCl}_{3} / \mathrm{CH}_{3} \mathrm{OH} / \mathrm{H}_{2} \mathrm{O}$ (10:3:0.5, $\mathrm{v} / \mathrm{v})$ to give seven fractions. Fraction $3(45 \mathrm{~g})$ was purified by column chromatography silica gel with $\mathrm{CHCl}_{3} / \mathrm{CH}_{3} \mathrm{OH} /$ $\mathrm{H}_{2} \mathrm{O}(5: 3: 1, \mathrm{v} / \mathrm{v})$ to give four fractions, fraction 2 were purified on RP-18 with $40 \% \rightarrow 100 \%$ aqueous $\mathrm{CH}_{3} \mathrm{OH}$, and on Sephadex LH-20 with $\mathrm{CH}_{3} \mathrm{OH} / \mathrm{CH}_{3} \mathrm{Cl}$ 1:1 to afford compound $1(17 \mathrm{mg})$, fraction 3 were purified on RP-18 with $30 \% \rightarrow 70 \%$ aqueous $\mathrm{CH}_{3} \mathrm{OH}$, and on Sephadex LH-20 with $\mathrm{CH}_{3} \mathrm{OH}$ to afford compound 2 (15 mg).

\section{Mollisside A}

White powder, $\mathrm{mp} 292-294^{\circ} \mathrm{C} ;[\alpha]_{\mathrm{D}}^{21}+6.3116(c 0.101$, $\left.\mathrm{CH}_{3} \mathrm{OH}\right) ; \mathrm{UV}\left(\mathrm{CH}_{3} \mathrm{OH}\right) \lambda_{\max } / \mathrm{nm}(\log \varepsilon): 193(3.587), 205$ (3.829), 277 (3.250); IR (KBr) $v_{\text {max }} / \mathrm{cm}^{-1}$ : 3420, 2937, 1166, 1074, 1020; ${ }^{1} \mathrm{H}$ NMR (400 MHz, $\mathrm{CD}_{3} \mathrm{OD}$ ) and ${ }^{13} \mathrm{C}$ NMR (100 MHz, $\mathrm{CD}_{3} \mathrm{OD}$ ) see Table 1; HRESIMS (negative ion) $m / z 483.2959$ [M-1] $]^{-}$(Calc. for $\mathrm{C}_{26} \mathrm{H}_{44} \mathrm{O}_{8}, 483.2957$ ); FABMS (negative ion) $m / z(\%) 483\left[\mathrm{M}^{-1}\right]^{-}(100), 391$ (5), 323 (15), 282 (5), 159 (6), 113 (5).

\section{Mollisside B}

White powder, $\mathrm{mp} 270-271^{\circ} \mathrm{C}$; $[\alpha]_{\mathrm{D}}^{21}-1.5989(\mathrm{c} 0.246$, $\left.\mathrm{CH}_{3} \mathrm{OH}\right) ; \mathrm{UV}\left(\mathrm{CH}_{3} \mathrm{OH}\right) \lambda_{\max } / \mathrm{nm}(\log \varepsilon): 196$ (3.393), 203 (4.108), 276 (2.890); IR (KBr) $v_{\text {max }} / \mathrm{cm}^{-1}: 3518,3380,3190$, 2980, 2930, 1691, 1607, 1073, 1037; ' ${ }^{\mathrm{H}} \mathrm{NMR}(500 \mathrm{MHz}$, $\left.\mathrm{CD}_{3} \mathrm{OD}\right)$ and ${ }^{13} \mathrm{C}$ NMR (125 MHz, CD OD) see Table 1; HRESIMS (positive ion) $\mathrm{m} / z 519.2565[\mathrm{M}+\mathrm{Na}]^{+}$(Calc. for $\left.\mathrm{C}_{26} \mathrm{H}_{40} \mathrm{O}_{9} \mathrm{Na}, 519.2570\right)$; FABMS (negative ion) $\mathrm{m} / z(\%)$ : 495[M-1] $]^{-}$(100), 400 (5), 335 (5), 281(6), 123 (4).

\section{Acid hydrolysis of compounds $\mathbf{1}$ and $\mathbf{2}$}

Compounds $1(3 \mathrm{mg})$ and $2(3 \mathrm{mg})$ in $50 \% \mathrm{MeOH}$ $(2 \mathrm{~mL})$ containing $5 \% \mathrm{HCl}$ were each heated in a boiling water-bath for $5 \mathrm{~h}$, then cooled for few minutes. The mixture was washed with EtOAc $(2 \times 2 \mathrm{~mL})$. The $\mathrm{H}_{2} \mathrm{O}$ layer was concentrated in vacuo to give a residue. The residue and authentic sugar were dotted to the plate developed with $\mathrm{CHCl}_{3} / \mathrm{CH}_{3} \mathrm{OH} / \mathrm{H}_{2} \mathrm{O}(5 / 3 / 0.5, \mathrm{v} / \mathrm{v})$, and phenylenediamineaniline-phosphoric acid used as spray reagent, followed by heating at $80{ }^{\circ} \mathrm{C}$. From compounds $\mathbf{1}$ and $\mathbf{2}$ glucose was detected, $\mathrm{R}_{\mathrm{f}}$ : glucose 0.45 .

\section{Supplementary Information}

Supplementary data including ${ }^{1} \mathrm{H},{ }^{13} \mathrm{C}$ NMR (DEPT), HMQC, HMBC, COSY, and ROSEY MS for compounds $\mathbf{1}$ and $\mathbf{2}$ are available free of charge at http://jbcs.sbq.org.br as PDF file.

\section{Acknowledgments}

This research was supported by the fund (P2008-ZZ22) of State Key Laboratory of Phytochemistry and Plant Resources in West China. We thank the analytical group of the State Key Laboratory of Phytochemistry and Plant Resources in West China, Kunming Institute of Botany, Chinese Academy of Sciences, for measurements of all spectra.

\section{References}

1. Committee of Flora of China; Flora of China, vol. 39, Science Press: Bejing, 1988, p.55.

2. Kinjo, J.; Fukui K.; Higuchi, H.; Nohara, T.; Chem. Pharm. Bull. 1991, 39, 1623.

3. Kinjo, J.; Higuchi, H.; Fukui, K.; Nohara, T.; Chem. Pharm. Bull. 1991, 39, 2952.

4. Higuchi, H.; Fukui, K.; Kinjo, J.; Nohara, T.; Chem Pharm. Bull. 1992, 40, 534.

5. Ito, A.; Kasai, R.; Yamasaki, K.; Duc, N.; Nham, N. T.; Phytochemistry 1994, 37, 1455.

6. Candy, H. A.; Brookes, K. B.; Bull, J. R.; McGarry, E. J.; McGarry, J. M.; Phytochemistry 1978, 17, 1681.

7. El-Mousallamy, A. M. D.; Phytochemistry 1998, 48, 759.

8. Pal, B. C.; Achari, B.; Yoshikawa, K.; Arihara, S.; Phytochemistry 1995, 38, 1287.

9. Debella, A.; Haslinger, E.; Schmid, M. G.; Bucar, F.; Michl, G.; Abebe, D.; Kunert, O.; Phytochemistry 2000, 53, 885.

10. Carpani, G.; Orsini, F.; Sisti, M.; Verotta, L.; Phytochemistry 1989, 28, 863.

11. Rukunga, G. M.; Waterman, P. G.; Phytochemistry 1996, 42, 1211.

12. Ueda, M.; Yamamura, S.; Tetrahedron Lett. 1999, 40, 7823.

13. Toshiko, S.; Takao, M.; Yasuhisa, S.; Chen, C. M.; Chem. Pharm. Bull. 1983, 31, 3865.

14. Liu, G.; Muller, R.; Ruedi, P.; Helv. Chim. Acta 2003, 86, 420. 


\section{Two New ent-Kaurane Diterpenoids from Albizia mollis (Wall.) Boiv.}

\section{Zhong-Quan Cheng, ${ }^{a, b}$ Dan Yang, ${ }^{a}$ Yu-Qing Liu, ${ }^{a}$ Jiang-Miao Hu, ${ }^{a}$ He-Zhong Jiang, ${ }^{a}$ Peng-Cheng Wang, ${ }^{a}$ Ning Li, ${ }^{c}$ Jun Zhou ${ }^{a}$ and You-Xing Zhao ${ }^{*, a}$}

${ }^{a}$ State Key Laboratory of Phytochemistry and Plant Resources in West China, Kunming Institute of Botany, the Chinese Academy of Sciences, Kunming 650204, P. R. China

${ }^{b}$ Graduate School of the Chinese Academy of Sciences, Beijing 100049, P. R. China

${ }^{c}$ School of Life Sciences, Anhui University, Hefei 230039, P. R. China

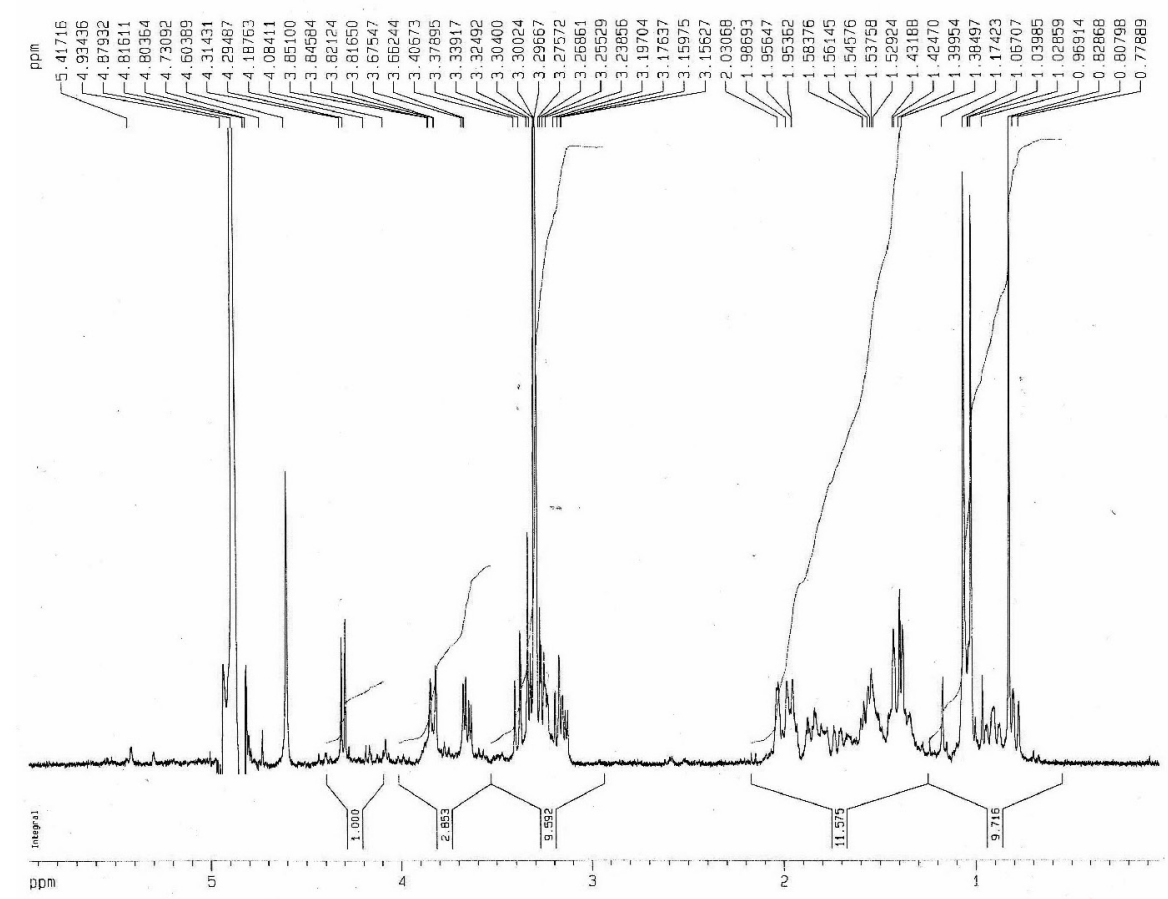

Figure S1. ' $\mathrm{H}$ NMR spectrum of $\mathbf{1}\left(400 \mathrm{MHz}, \mathrm{CD}_{3} \mathrm{OD}\right)$. 

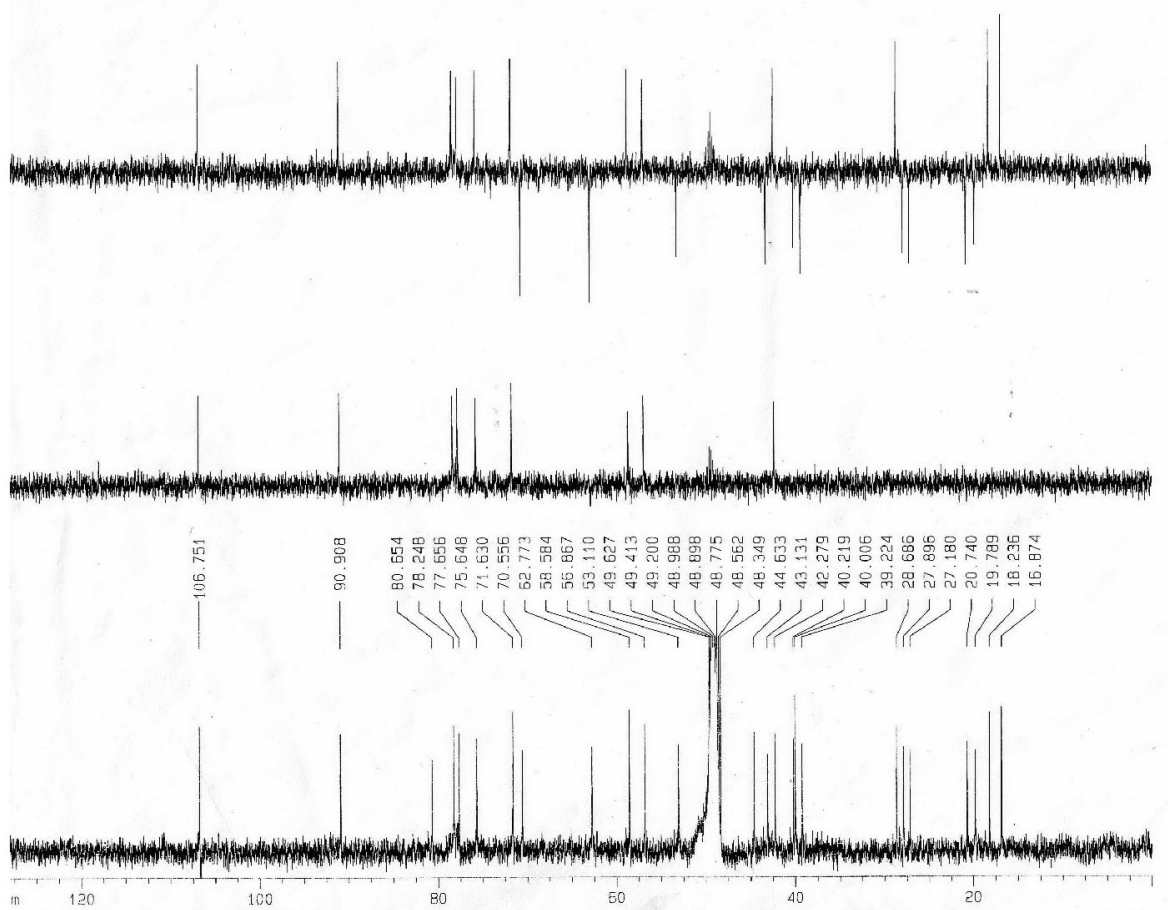

Figure S2. ${ }^{13} \mathrm{C}$ NMR spectrum of $\mathbf{1}\left(100 \mathrm{MHz}, \mathrm{CD}_{3} \mathrm{OD}\right)$.

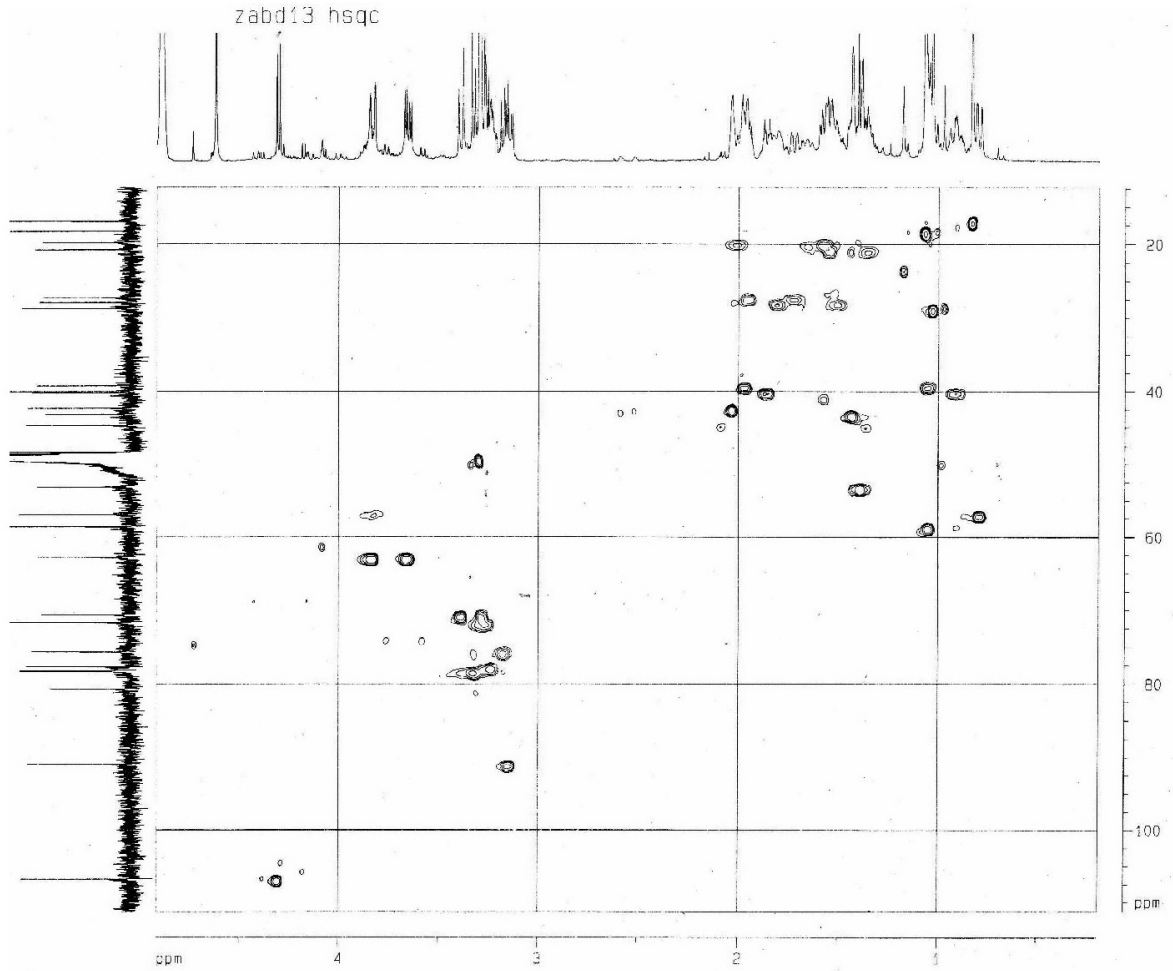

Figure S3. HSQC spectrum of $\mathbf{1}\left(\mathrm{CD}_{3} \mathrm{OD}\right)$. 


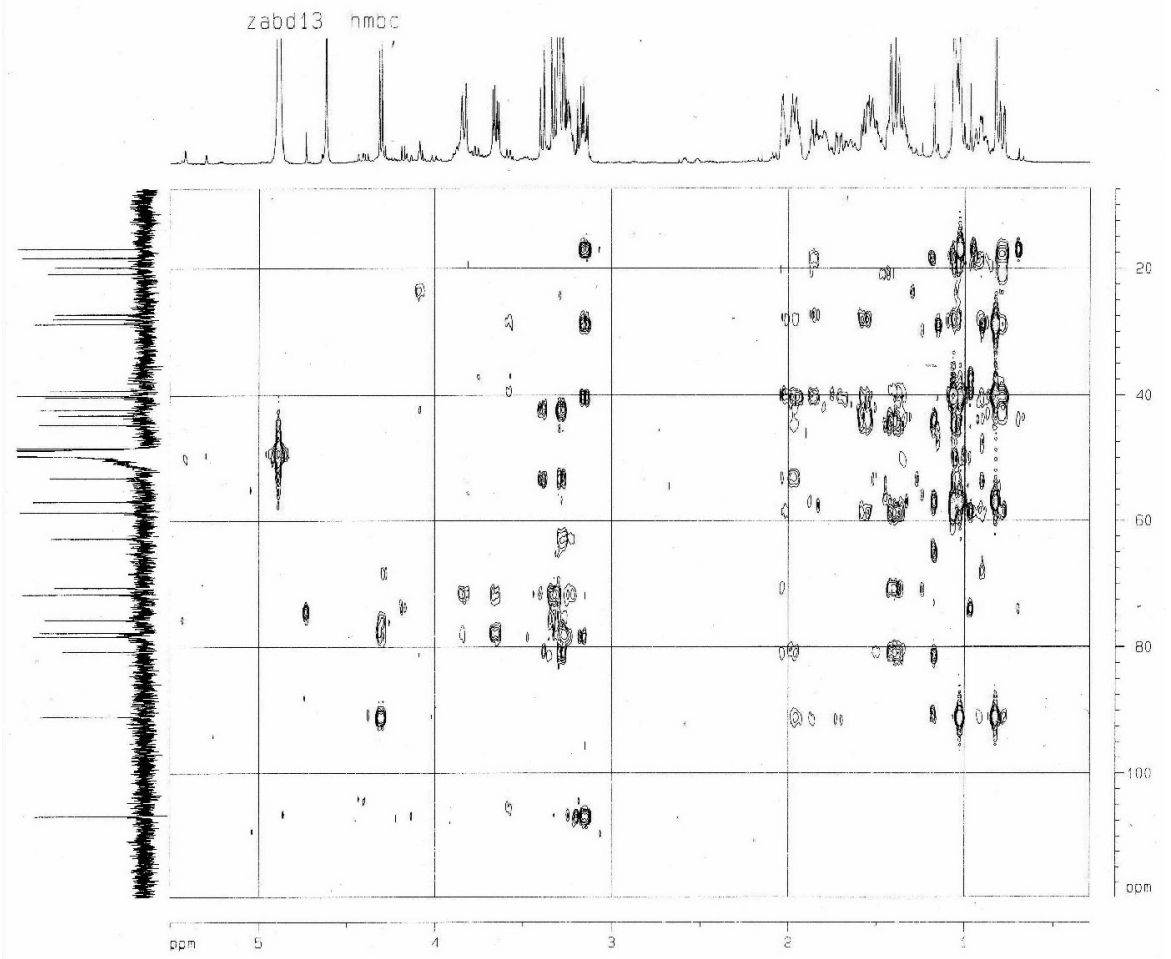

Figure S4. $\mathrm{HMBC}$ spectrum of $\mathbf{1}\left(\mathrm{CD}_{3} \mathrm{OD}\right)$.

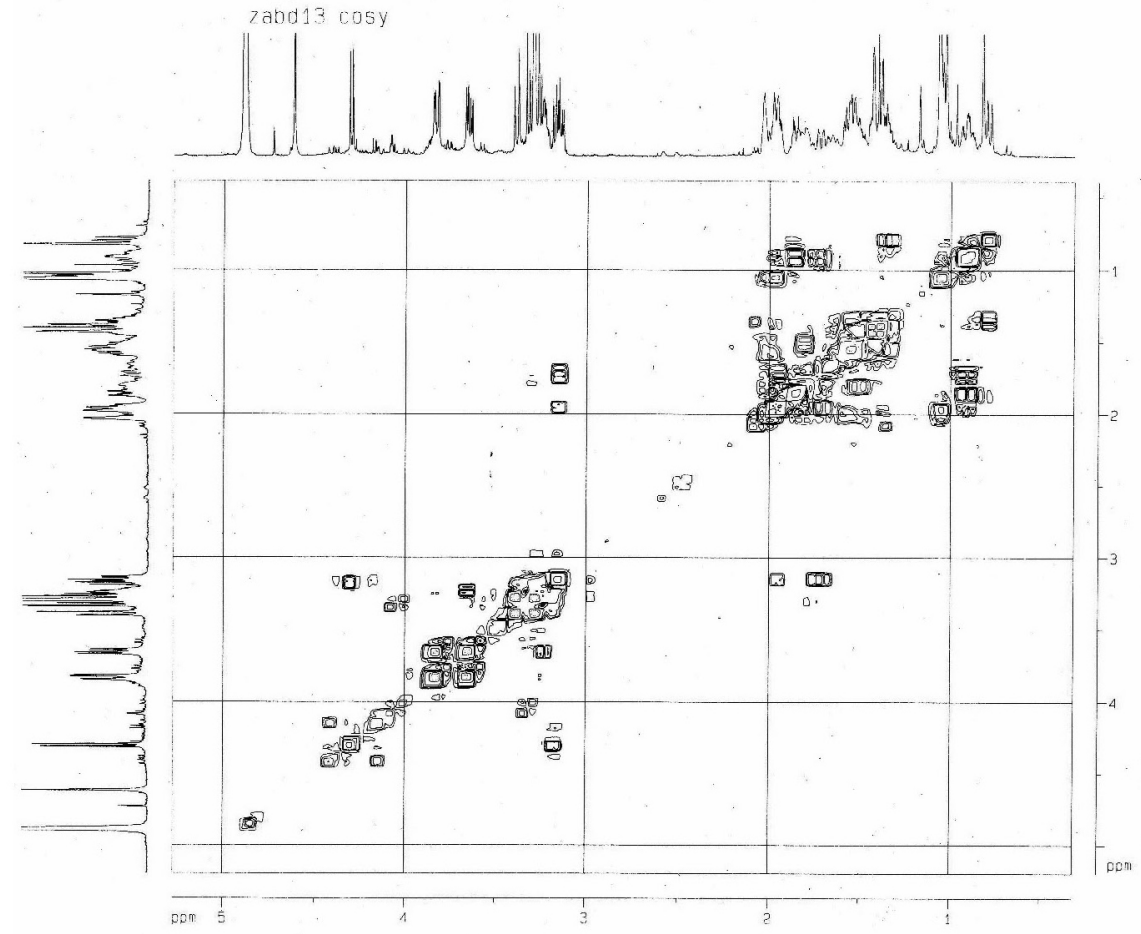

Figure S5. ${ }^{1} \mathrm{H},{ }^{1} \mathrm{H}$ COSY spectrum of $\mathbf{1}\left(\mathrm{CD}_{3} \mathrm{OD}\right)$. 


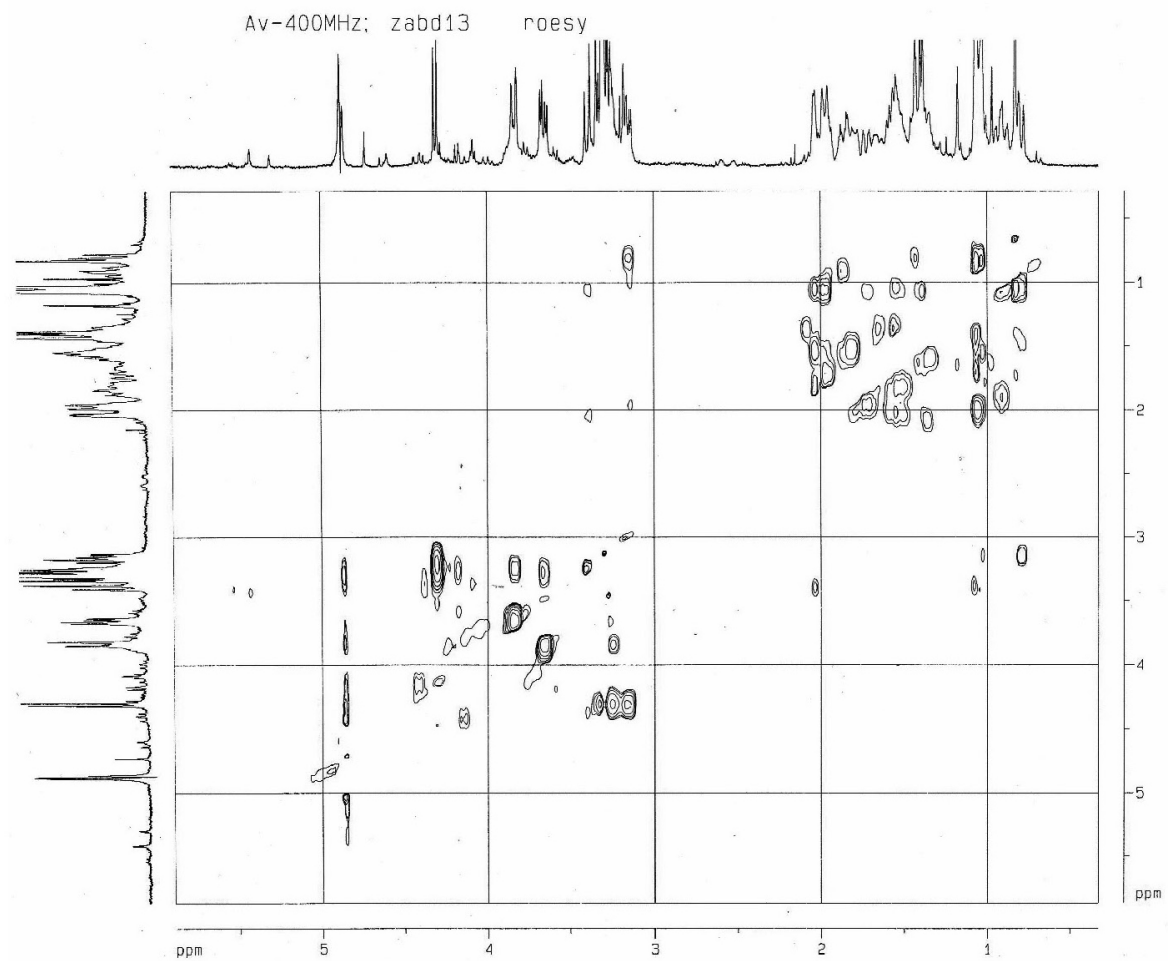

Figure S6. ROESY spectrum of $\mathbf{1}\left(\mathrm{CD}_{3} \mathrm{OD}\right)$.

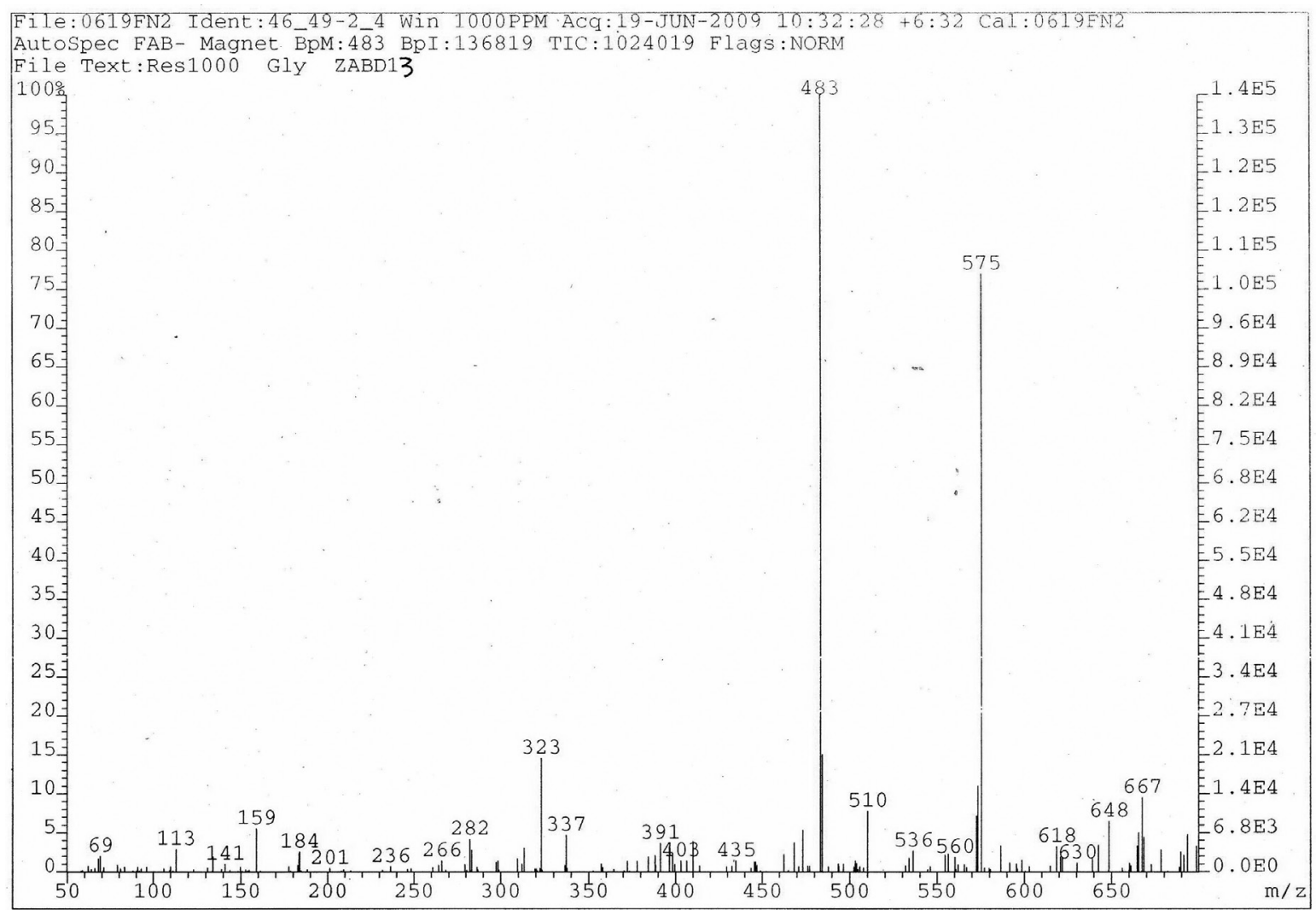

Figure S7. FABMS(-) spectrum of $\mathbf{1}\left(\mathrm{CD}_{3} \mathrm{OD}\right)$. 

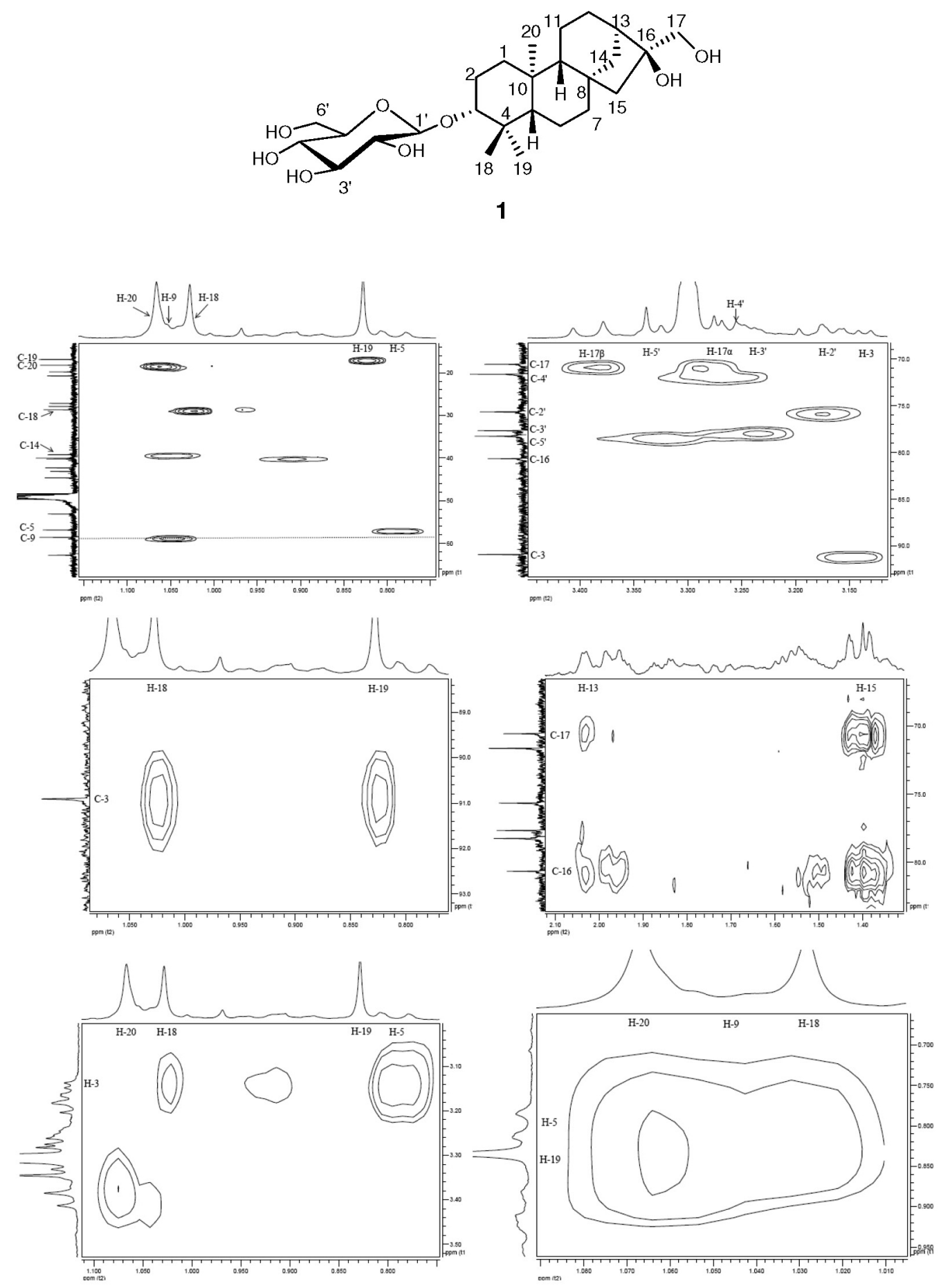

Figure S8. Key expansion 2D NMR spectra of $\mathbf{1}\left(\mathrm{CD}_{3} \mathrm{OD}\right)$. 


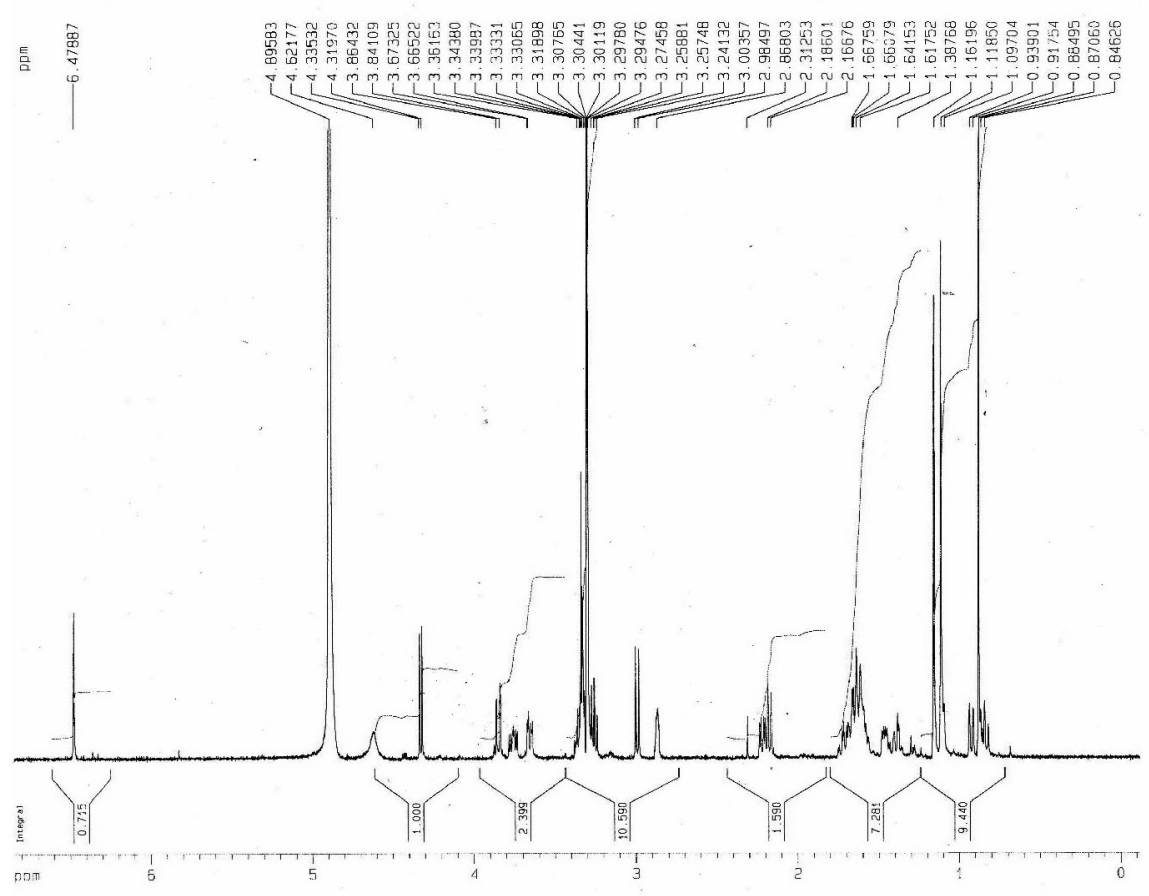

Figure S9. ${ }^{1} \mathrm{H}$ NMR spectrum of $\mathbf{2}\left(500 \mathrm{MHz}, \mathrm{CD}_{3} \mathrm{OD}\right)$.
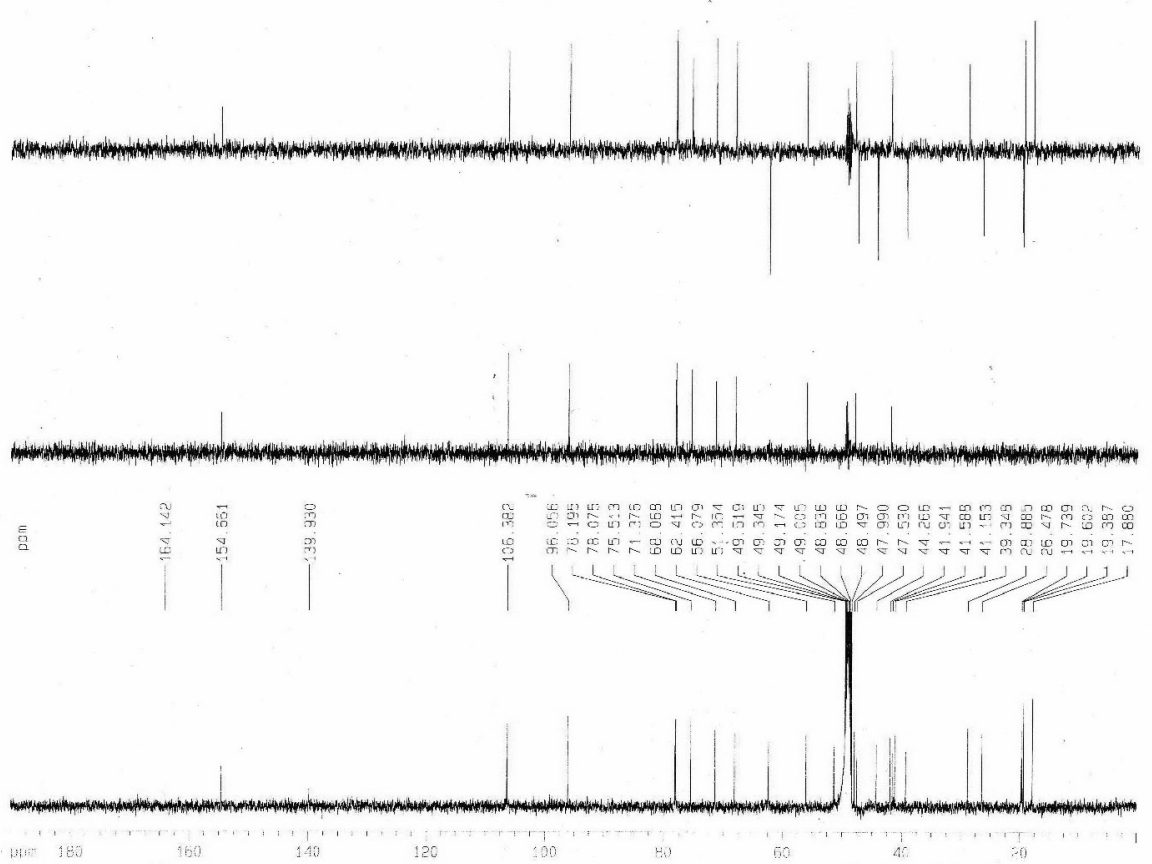

Figure S10. ${ }^{13} \mathrm{C}$ NMR (DEPT) spectrum of $2\left(125 \mathrm{MHz}, \mathrm{CD}_{3} \mathrm{OD}\right)$. 


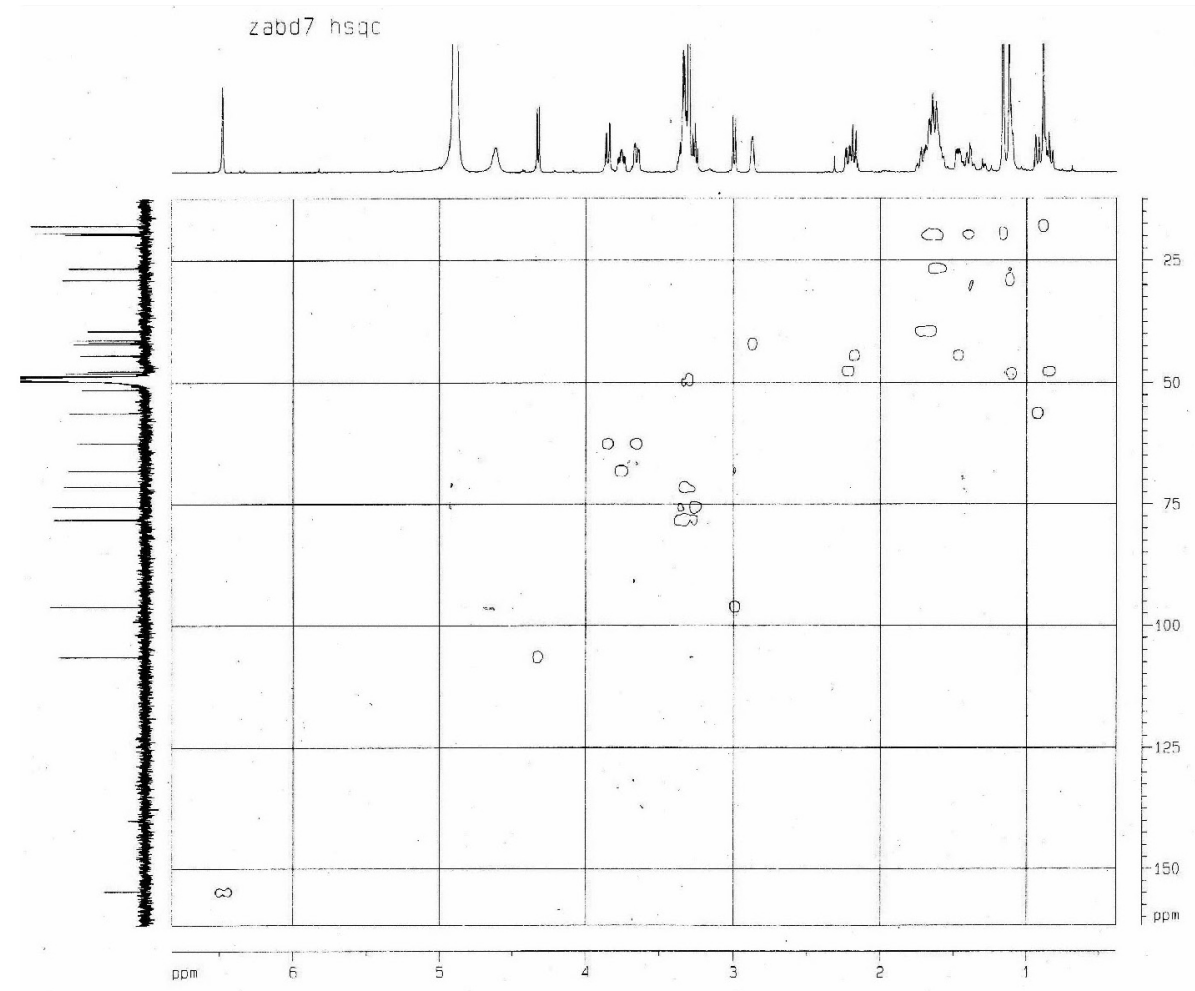

Figure S11. HSQC spectrum of $2\left(\mathrm{CD}_{3} \mathrm{OD}\right)$.

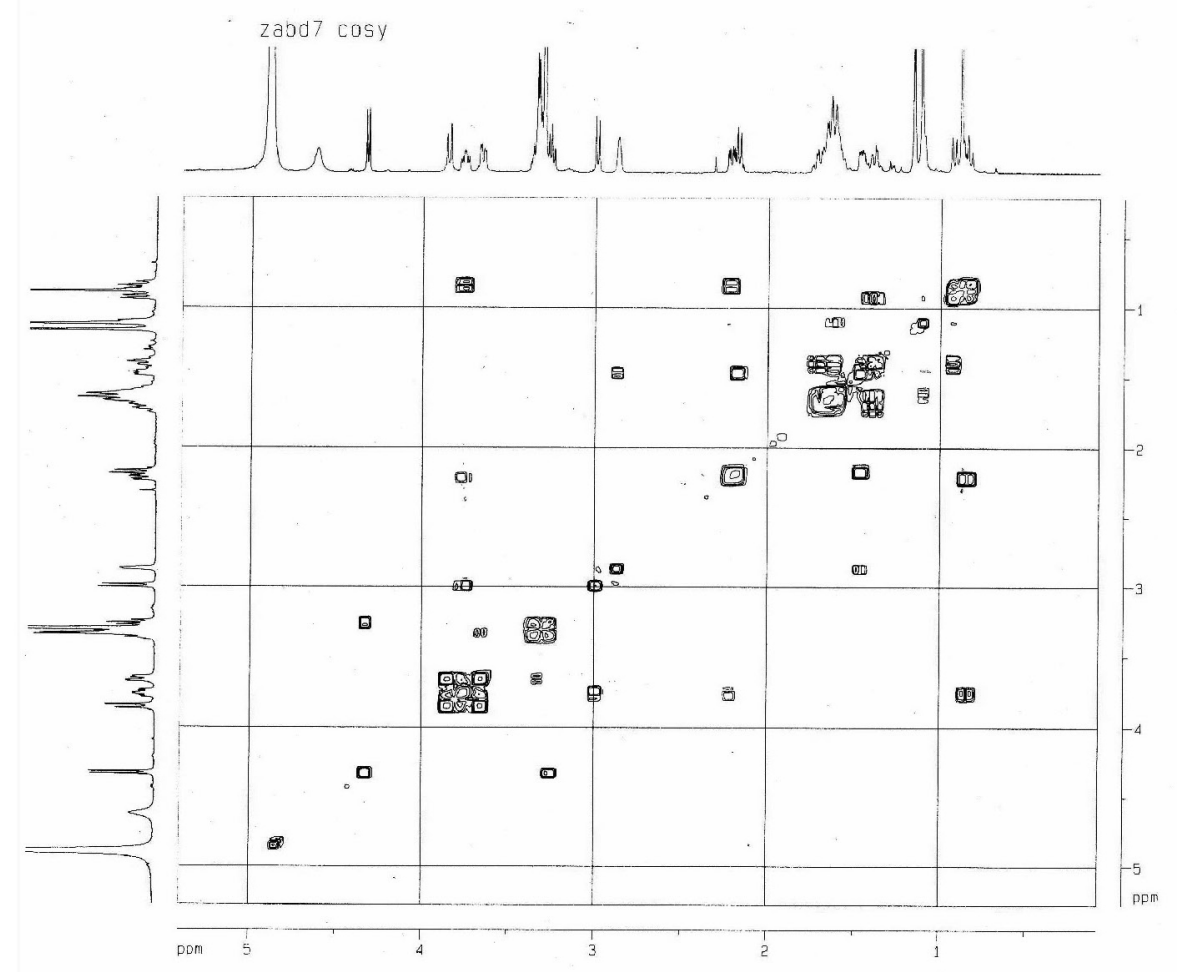

Figure S12. ${ }^{1} \mathrm{H},{ }^{1} \mathrm{H}$ COSY spectrum of $\mathbf{2}\left(\mathrm{CD}_{3} \mathrm{OD}\right)$. 


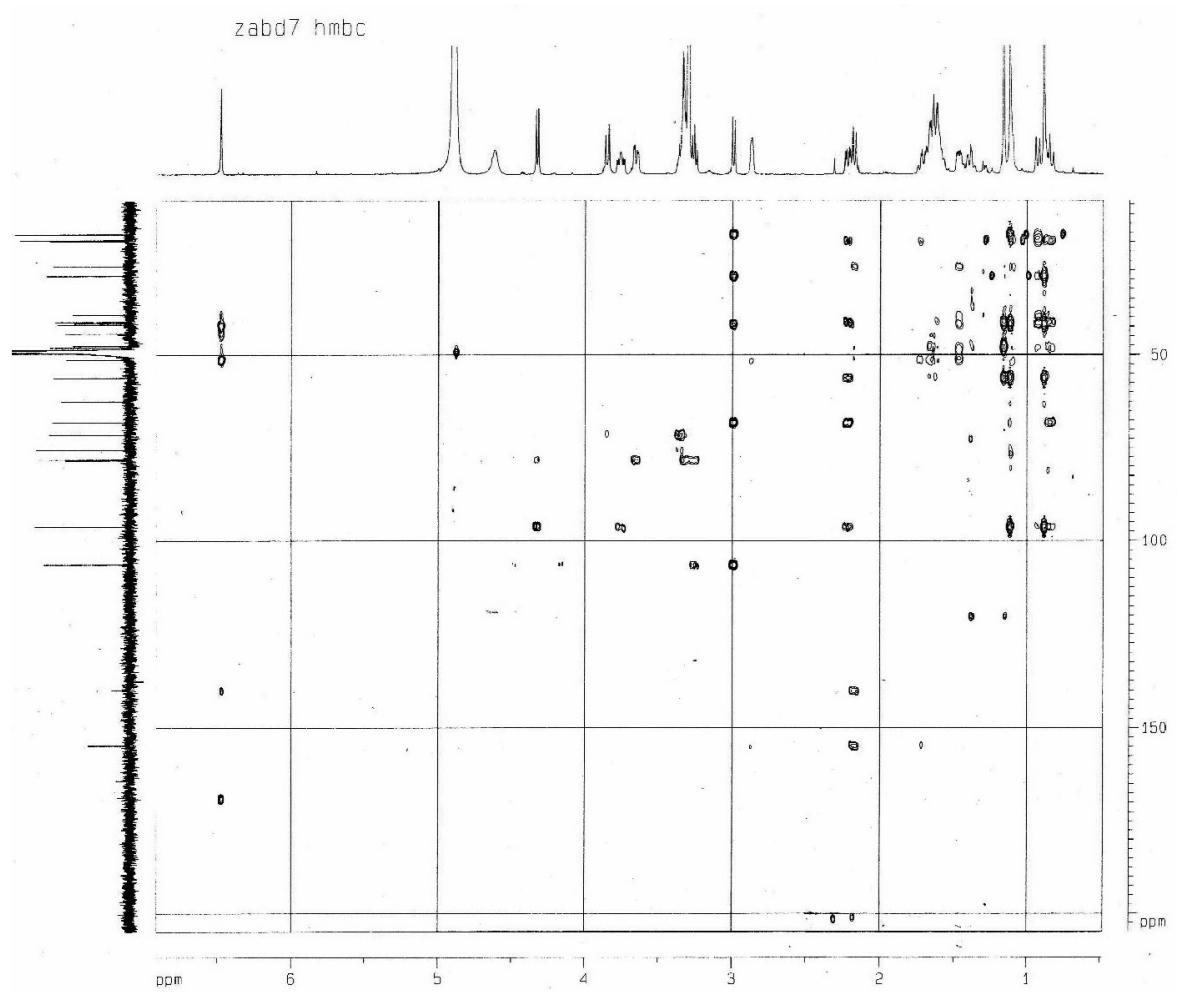

Figure S13. HMBC spectrum of $2\left(\mathrm{CD}_{3} \mathrm{OD}\right)$.

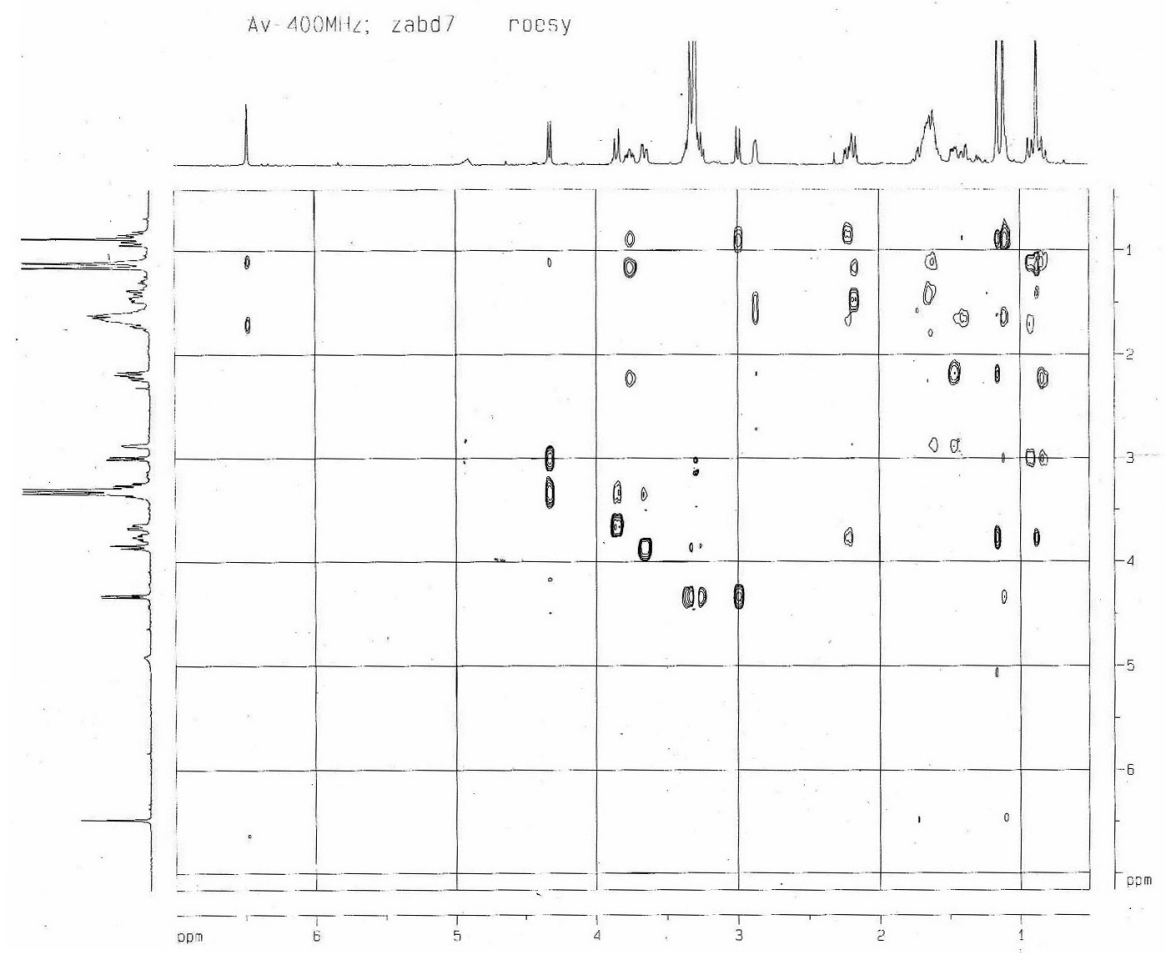

Figure S14. ROSEY spectrum of $2\left(\mathrm{CD}_{3} \mathrm{OD}\right)$. 


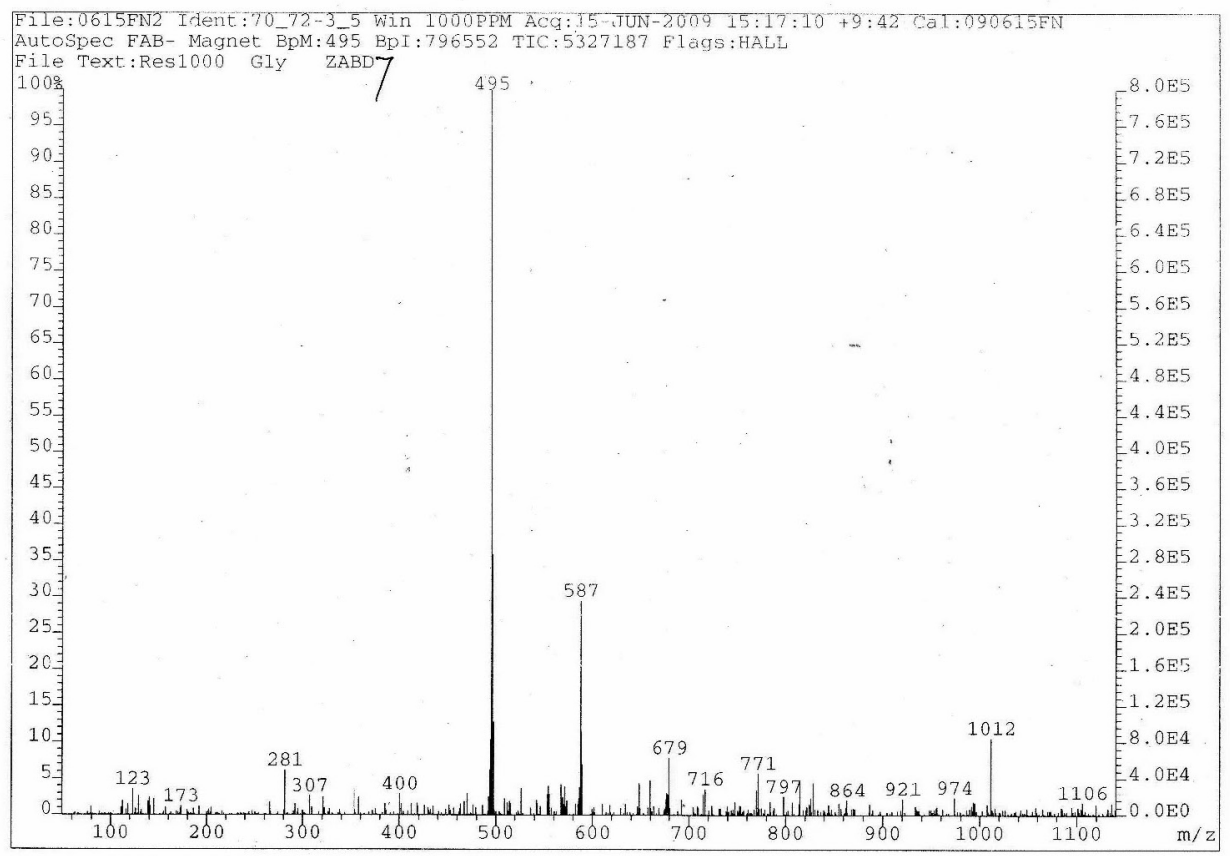

Figure S15. FABMS(-) spectrum of $\mathbf{2}\left(\mathrm{CD}_{3} \mathrm{OD}\right)$.

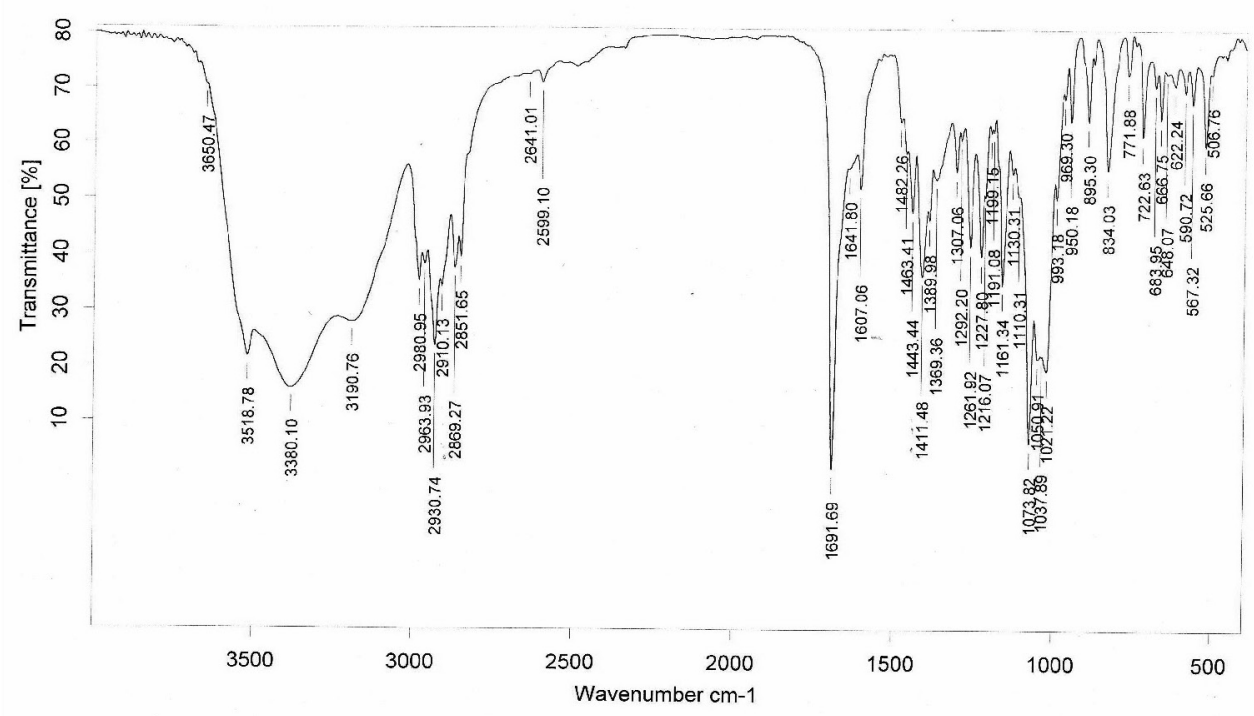

Figure S16. IR spectrum of $\mathbf{2}(\mathrm{KBr}$ pellet). 


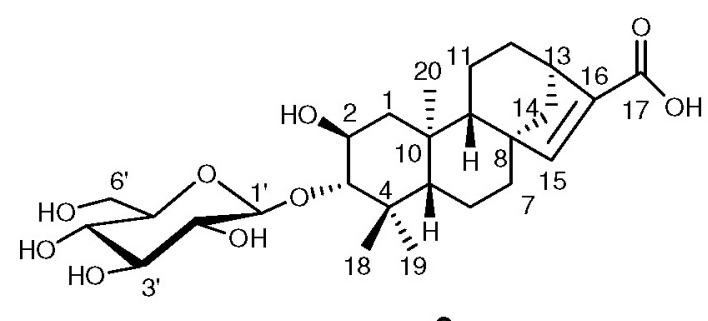

2
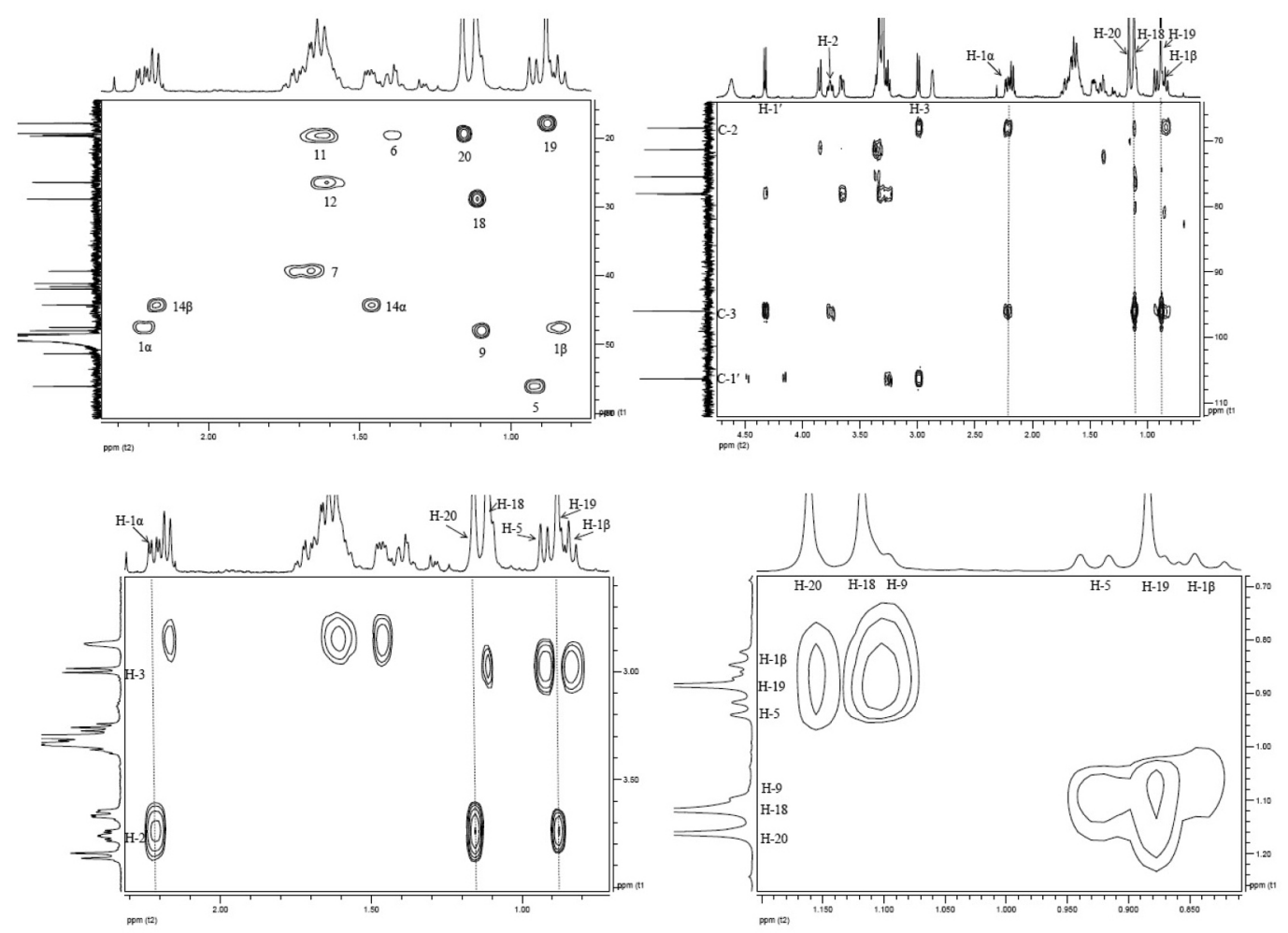

Figure S17. Key expansion 2D NMR spectra of $2\left(\mathrm{CD}_{3} \mathrm{OD}\right)$. 